\title{
Knowledge, Use and Recommendation of Iraqi Pharmacist Toward Complementary and Alternative Medicine
}

\section{Samer I. Mohammed ",1, Mohamed I. Al-Shadedi** and Ali A. Kasim***}

* Department of Clinical Pharmacy, College of Pharmacy, University of Baghdad, Baghdad, Iraq.

** Ministry of Health and Environment - Alrusafa Health Directorate , Pharmacy Department,

Herbal Medicines Unit, Baghdad, Iraq.

*** Department of Clinical Laboratory Sciences ,College of Pharmacy, University of Baghdad, Baghdad, Iraq.

\section{Abstract}

Over the past few decades, the global usage and applications of different kinds of complementary and alternative medicine are greatly exaggerated among the general population, this requires improving the knowledge of all health care provider including pharmacists toward proper and safe use of different complementary and alternative medicine modalities. The current study aims to assess the Iraqi pharmacists' knowledge, use, and recommendation toward complementary and alternative medicine .A cross-sectional pilot survey was done on a convenient sample of Iraqi pharmacists. Data were collected using a pretested questionnaire specifically designed from a previous study with some modification to reflect the work nature in Iraq. The most common complementary and alternative medicine modalities used personally by Iraqi pharmacists are nutritional supplements $(62 \%)$ followed by herbal products $(47 \%)$. On the other hand, nearly half $(48 \%)$ of pharmacists recommend some herbal products to their patients besides a slightly lower percentage (46\%) recommend nutritional supplements. The pharmacists' knowledge about several complementary and alternative medicine usages was low. The percentage of pharmacists who answered more than 8 questions properly from the 11 questions asked by the questionnaire was $(1.2 \%)$, while the percentage of pharmacists who answered correct answers for more than 7 questions was (5.6\%), and the percentage of pharmacists who have correct answers for more than half of the questions was only $(19.8 \%)$. This study points outs that despite the widespread use of some alternative and complementary medicine methods by pharmacists themselves or their patients, the level of knowledge is low in this area. Therefore, the study recommends the introduction of evidence-based information and updated guidelines for appropriate use of this type of medicine to pharmacy colleges' curricula to help future pharmacists meet demand from the growing number of alternative and complementary medicine users across Iraq.

Keywords: Complementary medicine, Alternative medicine, Herbal medicines, Nutritional supplements, Iraqi pharmacists.

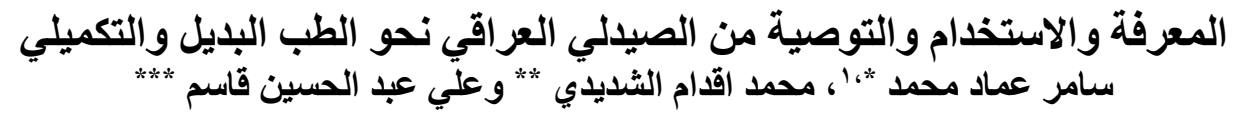

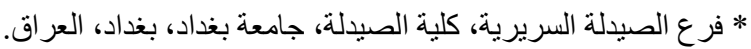

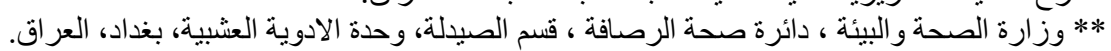

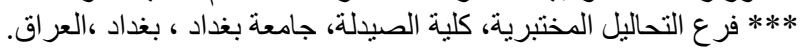

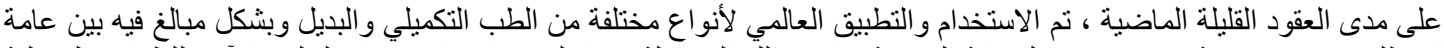

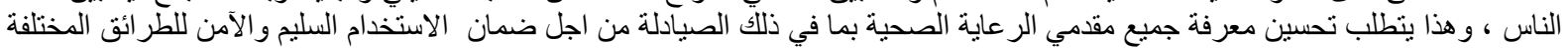

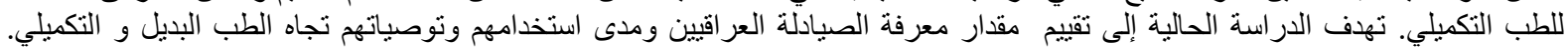

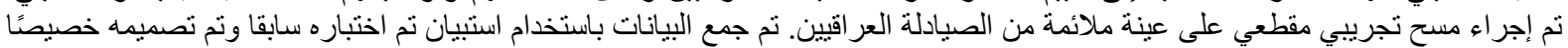

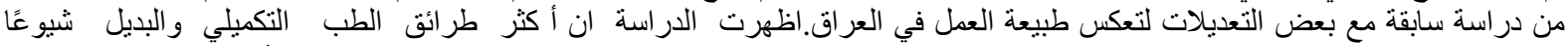

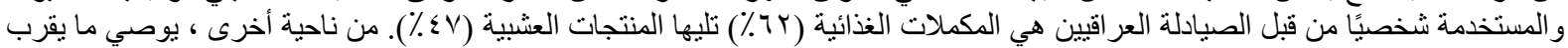

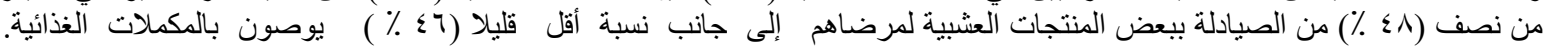

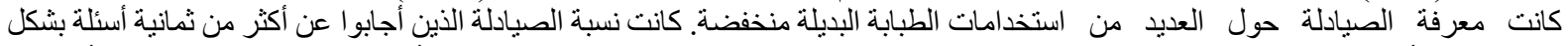

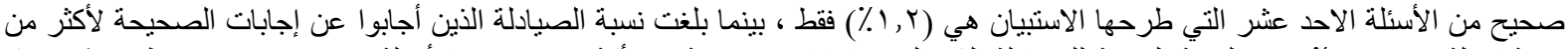

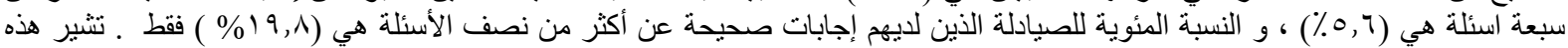

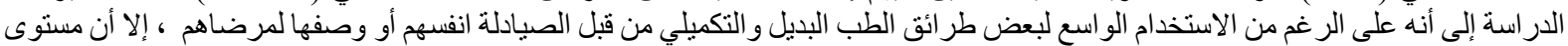

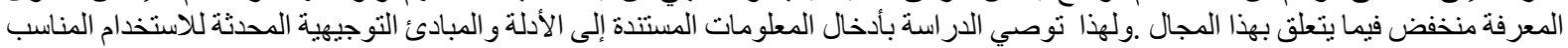

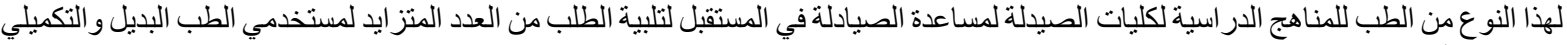

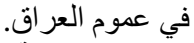
الكلمات المفتاحية: الطب التكميلي ,الطب البديل , الأدوية العشبية , المكملات الغذائية , الصيادلة العراقيون.

${ }^{1}$ Corresponding author E-mail: samer.jameel@copharm.uobaghdad.edu.iq

Received: 27/ 7 /2019

Accepted: 6/10/2019 


\section{Introduction}

Complementary and alternative medicine (CAM) is defined by The National Institute of Complementary Medicine as "a broad domain of healing resources that encompasses all health systems, modalities, and practices and their accompanying theories and beliefs, other than those intrinsic to the politically dominant health system of a particular society or culture in a given historical period"(1).

Complementary and alternative medicine is categorized into five main modules which are mind intermediations, body-based manipulation therapies, herbs or biologically based interventions (natural products), and energy based (metaphysical therapies) ${ }^{(2,3)}$.

For many reasons, the use of CAM among the general community has been increased over the past few decades. Most importantly is the internet that increased the availability and accessibility of information about CAM, as well as, contacts with other cultures that have local CAM modalities. Moreover, the general vision that CAM is safer and cheaper than conventional medications ${ }^{(4)}$. Complementary and alternative therapies are widely used in many countries of the world, especially among patients with chronic diseases $^{(5)}$. For economic and cultural reasons, CAM has been reported as a primary therapy in some populations ${ }^{(6,7)}$. The global prevalence of CAM use is ranging from $9.8 \%$ to $76.0 \%$ and varies greatly from country to country ${ }^{(8)}$; e.g., $38 \%$ among adults and approximately $12 \%$ among children in the United States ${ }^{(9)}, 51.8 \%$ in the United Kingdom ${ }^{(10)}, 68.9 \%$ in Australia ${ }^{(11)}$, and $74.8 \%$ in South Korea ${ }^{(12)}$. Unfortunately, the prevalence of CAM use in Iraq is not documented.

Despite the global widespread use of CAM therapies, their clinical efficacy is a subject of debate amongst many medical professionals. This can be attributed to the lack of scientific data regarding many CAM modalities, together with disparities in the knowledge level and evaluation of the available evidence about CAM amongst medical professionals. It has been shown that about $72 \%$ of patients do not reveal the use of CAM to their physicians ${ }^{(13)}$.

In addition of being in direct contact with patients, pharmacists are one of the most trusted medical professionals ${ }^{(13)}$.Hence, pharmacist have professional obligations to deliver quality information and guidance to patients about safe and effective use of all therapies, including
CAM. Taking into consideration that certain CAM therapies can interact or reduce efficacy of conventional medicine (14), pharmacists' knowledge toward CAM need to be based on up-to-date evidence based practice to fulfill these obligations.

In Iraq, the history of the traditional approach of therapy started from the Sumerian 5000 BC. (15). Nowadays, different CAM modalities are used by Iraqi patients for diverse diseases (16). Information about Iraqi pharmacists' knowledge toward CAM is lacking. Therefore, the aim of the current study is to assess the Iraqi pharmacists' knowledge, use and recommendation toward CAM.

\section{Subjects and Methods}

A cross-sectional pilot survey performed on a convenient sample of Iraqi pharmacists in different governorates of Iraq, the study was conducted from November 2018 to January 2019.

Data were collected using a pretested questionnaire specifically designed from a previous study with some modification to reflect the work nature in Iraq ${ }^{(17)}$. The questionnaire consisted of three sections: the first one collected the demographic data (the age, gender, educational level, work experience, and workplace) for the participants, the second section comprises beliefs and practice of participants in any type of CAM like [prayer/spiritual healing, herbal medicine, massage, nutritional supplements, cauterization, music, Al Hujama (cupping), bioelectromagnetic, homeopathy, acupuncture and aromatherapy]. While the third section designed to measure the knowledge of Iraqi pharmacists toward CAM.

\section{Statistical analysis}

The statistics of this study performed using the Microsoft Excel 2013 program; discrete variables are presented as numbers and frequencies.

\section{Results}

The questionnaire was administered to 232 Iraqi pharmacists as a hard copy and a soft copy to be filled online, the survey response rate was $100 \%$, and the demographic data for all participants are presented in table 1 . 
Table 1. The demographic data for participants. $(\mathrm{N}=\mathbf{2 3 2})$

\begin{tabular}{|c|c|c|c|}
\hline No & variable & Detail of variable & N0. (\%) \\
\hline \multirow[t]{2}{*}{1.} & \multirow[t]{2}{*}{ Gender } & Male & $75(32)$ \\
\hline & & Female & $157(68)$ \\
\hline \multirow[t]{3}{*}{2.} & \multirow[t]{3}{*}{ Age } & 23-30 years & $163(70)$ \\
\hline & & $31-40$ years & $40(17)$ \\
\hline & & $>40$ years & $29(13)$ \\
\hline \multirow[t]{4}{*}{3.} & \multirow[t]{4}{*}{ Qualification } & Bachelor & $200(86)$ \\
\hline & & Diploma & $7(3)$ \\
\hline & & Master & $11(5)$ \\
\hline & & $\mathrm{PhD}$ & $14(6)$ \\
\hline \multirow[t]{3}{*}{4.} & \multirow[t]{3}{*}{ Work experience } & $1-5$ years & $157(68)$ \\
\hline & & $6-10$ years & $33(14)$ \\
\hline & & $>10$ years & $42(18)$ \\
\hline \multirow[t]{4}{*}{5.} & \multirow[t]{4}{*}{ Workplace } & Pharmacy & $57(25)$ \\
\hline & & Hospital & $131(56)$ \\
\hline & & College & $22(9)$ \\
\hline & & Else & $22(9)$ \\
\hline
\end{tabular}

The pattern of use and recommendation present study were summarized in table 2 . behaviors of CAM among pharmacists in the

Table 2. The usage and recommendation behaviors of CAM among pharmacists. $(\mathrm{N}=232)$

\begin{tabular}{|l|l|l|l|l||}
\hline CAM Modalities & $\begin{array}{l}\text { Usage } \\
(\mathbf{n})\end{array}$ & $\begin{array}{l}\text { Percentage } \\
(\%)\end{array}$ & Recommendation (n) & $\begin{array}{l}\text { Percentage } \\
(\%)\end{array}$ \\
\hline Prayer/spiritual healing & 96 & 41 & 95 & 41 \\
\hline Herbal medicine & 110 & 47 & 111 & 48 \\
\hline Massage & 91 & 39 & 87 & 38 \\
\hline Nutritional supplements & 143 & 62 & 106 & 46 \\
\hline Cauterization & 19 & 8 & 42 & 18 \\
\hline Music & 70 & 30 & 61 & 26 \\
\hline Cupping- Al Hujama & 31 & 13 & 77 & 33 \\
\hline Bio-electromagnetic & 10 & 4 & 31 & 13 \\
\hline Homeopathy & 10 & 4 & 12 & 5 \\
\hline Acupuncture & 21 & 9 & 26 & 11 \\
\hline Aromatherapy & 32 & 14 & 32 & 14 \\
\hline \hline
\end{tabular}

Regarding the pharmacists' responses to knowledge-based items about various CAM uses which shown in table 3, this study showed a low level of knowledge about CAM and the percentage of pharmacists who answered more than 8 questions correctly from the 11 questions asked by the questionnaire was $(1.2 \%)$ which represents only three participants, while the percentage of pharmacists who answered correct answers for more than 7 questions of the questions was $(5.6 \%)$ which represents thirteen participants, and the percentage of pharmacists who have correct answers for more than half of the questions was only $(19.8 \%)$ which represents (46) participants . 
Table 3. Pharmacists' responses on knowledge-based items about different CAM uses

\begin{tabular}{|c|c|c|c|}
\hline \multirow[t]{2}{*}{ Variable } & \multicolumn{3}{|c|}{$\begin{array}{c}\text { Pharmacists }(\mathrm{n}=232) \\
\text { N }(\%)\end{array}$} \\
\hline & True & False & $\begin{array}{l}\text { Don't } \\
\text { know }\end{array}$ \\
\hline $\begin{array}{l}\text { Alternative medicines are used instead of conventional } \\
\text { medicine }\end{array}$ & $85(37)$ & $65(28) *$ & $82(35)$ \\
\hline $\begin{array}{l}\text { The use of ginger, thyme, and green tea in the first } \\
\text { trimester of pregnancy is totally safe. }\end{array}$ & $39(17)$ & $104(45) *$ & $89(38)$ \\
\hline Ginseng is commonly used as a general health tonic & $144(62) *$ & $27(12)$ & $61(26)$ \\
\hline Capsaicin relieves arthritis pain & $111(48) *$ & $21(9)$ & $100(43)$ \\
\hline Hijama is a popular method used in Iraq & $180(78) *$ & $12(5)$ & $40(17)$ \\
\hline Frankincense is used as an antispasmodic & $10(4) *$ & $40(17)$ & $187(81)$ \\
\hline Ginger can be used as an analgesic. & $46(20) *$ & $94(41)$ & $92(40)$ \\
\hline $\begin{array}{l}\text { It's safer to use alternative medicines along with } \\
\text { conventional medicine. }\end{array}$ & $32(14) *$ & $78(34)$ & $122(53)$ \\
\hline Herbal medicines are free of side effects. & $4(2)$ & $222(96) *$ & $6(3)$ \\
\hline Caffeine is used to treat insomnia. & $11(5)$ & $204(88) *$ & $17(7)$ \\
\hline Peppermint is used as an antimicrobial & $62(27) *$ & 101(44) & $69(30)$ \\
\hline
\end{tabular}

* Percentage of respondents who got the questions correct on each knowledge question.

\section{Discussion}

Obviously, CAM is going to be part of health care for much of the population in the very near future; this is augmented by the rapidly growing research base in this realm. ${ }^{(18)}$ Being key healthcare providers, pharmacists have a professional obligation to deliver quality information, advice and guidance to their patients including those using CAM. This study was designed to assess the knowledge, use and recommendation of Iraqi pharmacists toward CAM.

Most of the participant pharmacists in the study were female $(68 \%)$, and the predominant age group being between 23 and 30 years $(70 \%)$; this points short years of practice but more fresh academic information. The results of the current study showed that the most common CAM modalities used by Iraqi pharmacists were nutritional supplements (62\%), herbal medicine $(47 \%)$ and praying and spiritual healing $(41 \%)$. While the most common CAM modalities recommended were herbal medicine (48\%), nutritional supplements $(46 \%)$ and praying and spiritual healing (41\%) Other studies showed different pharmacists' priorities in using or recommending CAM modalities. AlBedah, et al. showed that prophetic medicine including prayer, honey and bee products, herbal medicine and hujama, are the most important CAM modalities used by health professionals, including pharmacists, in the Riyadh region, Saudi Arabia. ${ }^{(19)}$ Similarly, in Iranian study, herbal medicine, hujama and massage therapy were the most frequently recommended CAM modalities. ${ }^{(20)}$ The religious values and cultural believes seem to have a significant impact in this regard. In Palestine, pharmacists are recommending exercises and nutritional supplements as the two major recommended CAM modalities. ${ }^{(21)}$ On the other hand, Western researches showed that the most accepted CAM modalities were acupuncture, relaxation techniques, chiropractic, and massage therapy. ${ }^{(22-24)}$ Lack of knowledge and the inadequate number of trained personnel to use certain CAM modalities may be the main barriers toward using or recommending them.

Regarding the knowledge of Iraqi pharmacists toward CAM, the results showed that only $19.8 \%$ of the participants have answered more than half of the administered questions correctly. This indicates very poor knowledge; taking into consideration that most of the participants had graduated from college within less than seven years period (as discussed earlier), which supposedly means they have considerably fresh academic information. Other studies carried out in Lebanon $^{(25)}$, Palestine ${ }^{(21)}$, and Saudi Arabia ${ }^{(26)}$ showed fair knowledge of pharmacist toward CAM. Inadequate level of knowledge may reflect the need to improve the undergraduate curriculum, and to involve pharmacists into well-structured training programs and postgraduation courses of CAM. Finally, a study conducted in 2003 in Singapore among pharmacists attending the 61st International Congress of International Pharmaceutical 
Federation (FIP), more specific those joining the Singapore Traditional Chinese Medicine Research Symposium, showed a good knowledge of pharmacists toward CAM. ${ }^{(27)}$ Apparently, pharmacists participating in the symposium whom surveyed in the study had good expertise toward CAM.

The increasing number of CAM users in the general population of Iraq represents a challenge to Iraqi pharmacists. Therefore, pharmacists need to integrate more information about the correct use and specialized guidelines about CAM into their continuing professional development plan to expand their awareness and skills in dealing with this growing aspect of therapy.

\section{Ethical statement}

The study and the questionnaire was validated by the local Scientific and Ethical Committee in College of Pharmacy, Baghdad University. Verbal consent was obtained from all participants included in the study. The authors informed the participants about the purpose of the study at the beginning of each interview. Meanwhile, the respondents were informed that their participation was voluntary and they were allowed to withdraw themselves at any point of time during the interview.

\section{References}

1. National Institute of Complementary Medicine. Understanding Complementary Medicine. 2007 [cited 2019 July 1st.]. Available from: http :// www .nicm .edu .au /health_information/information_for_cons umers/.

2. Tindle HA, Davis RB, Phillips RS, Eisenberg DM. Trends in use of complementary and alternative medicine by US adults: 1997-2002. Alternative Therapies in Health and Medicine. 2005;11(1):42-9.

3. Roush RA. Complementary and Alternative Medicine.: Routledge; 2016.

4. Ventola CL. Current Issues Regarding Complementary and Alternative Medicine (CAM) in the United States: Part 1: The Widespread Use of CAM and the Need for Better-Informed Health Care Professionals to Provide Patient Counseling. $\mathrm{P} \mathrm{T}$. 2010;35(8):461-8.

5. Mollaoglu M, Aciyurt A. Use of complementary and alternative medicine among patients with chronic diseases 2013 . 181-8 p.

6. Nunkoo DH, Mahomoodally MF. Ethnopharmacological survey of native remedies commonly used against infectious diseases in the tropical island of Mauritius. Journal of Ethnopharmacology. 2012;143(2):548-64.
7. Suroowan S, Mahomoodally F. Complementary and alternative medicine use among Mauritian women. Complementary Therapies in Clinical Practice. 2013;19(1):36-43.

8. Harris PE, Cooper KL, Relton C, Thomas KJ. Prevalence of complementary and alternative medicine (CAM) use by the general population: a systematic review and update. International Journal of Clinical Practice. 2012;66(10):924-39.

9. Barnes PM, Bloom B, Nahin RL. Complementary and alternative medicine use among adults and children: United States, 2007. National Health Statistics Reports. 2008(12):1-23.

10. Posadzki P, Watson LK, Alotaibi A, Ernst E. Prevalence of use of complementary and alternative medicine (CAM) by patients/consumers in the UK: systematic review of surveys. Clinical Medicine. 2013;13(2):126-31.

11. Xue CC, Zhang AL, Lin V, Da Costa C, Story DF. Complementary and alternative medicine use in Australia: a national population-based survey. Journal of Alternative and Complementary Medicine. 2007;13(6):643-50.

12. Ock SM, Choi JY, Cha YS, Lee J, Chun MS, Huh $\mathrm{CH}$, et al. The use of complementary and alternative medicine in a general population in South Korea: results from a national survey in 2006. Journal of Korean Medical Science. 2009;24(1):1-6.

13. Eisenberg DM, Kessler RC, Van Rompay MI, Kaptchuk TJ, Wilkey SA, Appel S, et al. Perceptions about complementary therapies relative to conventional therapies among adults who use both: results from a national survey. Annals of Internal Medicine. 2001;135(5):344-51.

14. Elmer GW, Lafferty WE, Tyree PT, Lind BK. Potential interactions between complementary/alternative products and conventional medicines in a Medicare population. The Annals of Pharmacotherapy. 2007;41(10):1617-24.

15. Chiappelli F, Prolo P, S Cajulis O. Evidence-based Research in Complementary and Alternative Medicine I: History2006. 453-8 p.

16. Bodeker G OC. WHO global atlas of traditional, complementary and alternative medicine. World Health Organization; 2005.

17. Mohammed Al-Hinai S, Haridass S, Hassali M, Nouri A, Verma A. Knowledge, attitude, and use of complementary and alternative medicine (CAM) among 
pharmacy and nursing students in Oman.Homeopathy;2018. 40-3 p.

18. Lewith G, Verhoef M, Koithan M, Zick SM. Developing CAM Research Capacity for Complementary Medicine. Evidencebased complementary and Alternative Medicine : eCAM. 2006;3(2):283-9.

19. Albedah AM, El-Olemy AT, Khalil MK. Knowledge and attitude of health professionals in the Riyadh region, Saudi Arabia, toward complementary and alternative medicine. Journal of Family and Community Medicine. 2012;19(2):93-9.

20. Adib-Hajbaghery M, Hoseinian $M$. Knowledge, attitude and practice toward complementary and traditional medicine among Kashan health care staff, 2012. Complementary Therapies in Medicine. 2014;22(1):126-32.

21. Shraim NY, Shawahna R, Sorady MA, Aiesh BM, Alashqar GS, Jitan RI, et al. Community pharmacists' knowledge, practices and beliefs about complementary and alternative medicine in Palestine: a cross-sectional study. BMC complementary and Alternative Medicine. 2017;17(1):429.

22. Brown CM, Pena A, Resendiz K. Pharmacists' actions when patients use complementary and alternative medicine with medications: A look at Texas-Mexico border cities. Journal of the American
Pharmacists Association : JAPhA. 2011;51(5):619-22.

23. Brown CM, Barner JC, Shah S. Community pharmacists' actions when patients use complementary and alternative therapies with medications. Journal of the American Pharmacists Association : JAPhA. 2005;45(1):41-7.

24. Harris IM, Kingston RL, Rodriguez R, Choudary V. Attitudes towards complementary and alternative medicine among pharmacy faculty and students. Am J Pharm Educ. 2006;70(6):129.

25. Hijazi MA, Shatila H, El-Lakany A, Aboul Ela M, Kharroubi S, Alameddine M, et al. Beliefs, practices and knowledge of community pharmacists regarding complementary and alternative medicine: national cross-sectional study in Lebanon. BMJ open. 2019;9(3):e025074.

26. Alnaim L, Almazrou S, Alsunbul M, Alhaji A, Alenazi A, Alboami S. Pharmacist's knowledge and attitudes towards complementary and alternative medicine in Saudi Arabia: A cross-sectional study. Advances in Integrative Medicine. 2018;5(3):96-102.

27. Koh HL, Teo HH, Ng HL. Pharmacists' patterns of use, knowledge, and attitudes toward complementary and alternative medicine. Journal of Alternative and Complementary Medicine. 2003;9(1):5163.

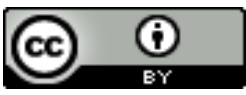

Baghdad Iraqi Journal Pharmaceutical Sciences by bijps is licensed under a Creative Commons Attribution 4.0 International License. Copyrights(C 2015 College of Pharmacy - University of Baghdad. 